\title{
The Effects of Scapulothoracic Mobilization in Patients with Neck Pain and Scapular Dyskinesis: A Single-Blind, Randomized, Clinical Trial
}

\author{
Ali M. Alshami ( $\square$ alshami@iau.edu.sa ) \\ Imam Abdulrahman Bin Faisal University https://orcid.org/0000-0003-3263-8896 \\ Abrar I. AlSadiq
}

\section{Research}

Keywords: Manual therapy, mobilization with movement, pressure pain threshold, physical therapy

Posted Date: July 17th, 2020

DOI: https://doi.org/10.21203/rs.3.rs-41441/v1

License: (c) (i) This work is licensed under a Creative Commons Attribution 4.0 International License.

Read Full License 


\section{Abstract}

Background: No studies are available on the effects of scapulothoracic mobilization with neck movement (MWM) on patients with neck pain and scapular dyskinesis. Objective: To investigate the effects of scapulothoracic MWM on neck pain, range of motion (ROM), and function in patients with neck pain who demonstrated scapular dyskinesis.

Methods: This was a single-blind, randomized, clinical trial. Forty participants with neck pain and scapular dyskinesis were randomly assigned to one of two 2-week regimens: experimental (scapulothoracic MWM + corrective exercises + tape) or comparison (corrective exercises + tape). The visual analog scale (VAS), pressure pain threshold (PPT), cervical and scapular ROM, and Neck Disability Index (NDI) were measured at baseline, after the third session, and after the sixth session.

Results: Pain decreased after the sixth session in both the experimental [mean difference: $3.1 ; 95 \%$ confidence interval (Cl): 2.1-4.1] and comparison groups (1.8; 95\% Cl: 0.81-2.8). PPT and scapular ROM did not change in either group at any session. After the sixth session, the ROM of neck extension, right rotation, and right and left side bending improved significantly ( $p £ 0.031$ ) in both groups, but did not reach the minimal detectable change. The NDI improved in both the experimental $(7.2-10.6 ; 95 \% \mathrm{Cl}$ : $2.5-$ 15.7) and comparison groups (5.9-10.3; 95\% Cl: 1.2-15.4). There were no significant differences between the groups in any outcome measure at any session.

Conclusions: Adding scapulothoracic MWM to corrective exercises and tape over a 2-week period did not seem to add benefit for pain and function in patients with neck pain with scapular dyskinesis.

Trial registration: ClinicalTrials.gov, NCT03046160. Registered 8 February 2017 - Retrospectively registered, https://clinicaltrials.gov/ct2/show/NCT0304616

\section{Introduction}

Neck pain is common, with a global point prevalence of $4.9 \%$. It ranked the fourth highest cause of disability explained by disability-adjusted life years that increased from 23.9 million to 33.6 million between 1990 and 2010 [1]. In Saudi Arabia, the prevalence of neck pain among patients who were diagnosed with a neck disorder was estimated to be $35.8 \%$ from 2011 to 2013 [2].

The evaluation of patients with neck pain should include assessments of impairments of body function such as mobility deficits in the cervical and thoracic spine, neural involvement, and movement coordination impairments [3]. Scapular dysfunction has been associated with neck pain [4]. Scapular dysfunction refers to an altered resting position and/or movement of the scapula, which has been termed 'scapular dyskinesis' [5]. The relevance of scapular dyskinesis in pain is mostly dependent on clinical observation rather than on scientific evidence [4]. Although several studies have investigated scapular dyskinesis in patients with shoulder conditions [5-9], few studies have explored the relationship between scapular dyskinesis and neck pain[10-12]. 
Several physical therapy interventions have been recommended for patients with neck pain. These interventions include, but are not limited to, neck and/or scapulothoracic range of motion (ROM) exercises, stretching, strengthening, and endurance exercises; aerobic training; dry needling; laser therapy; intermittent mechanical/manual traction; patient education and reassurance; and manual therapy. Manual therapy included mobilization and manipulation techniques that were applied mainly to the cervical and/or thoracic spine [3]. For scapular dyskinesis, Ellenbecker and Cools [13] suggested a treatment algorithm, in which neuromuscular coordination and strength training are recommended for patients with lack of muscle performance, whereas flexibility deficits are addressed by stretching and mobilization techniques.

The mobilization techniques that were recommended for scapular dyskinesis included manual stretching, soft-tissue techniques, accessory mobilization, and mobilization with movement (MWM) [13]. MWM is a manual therapy technique, during which a sustained specific force/glide is applied to a joint by the therapist while the patient actively performs a previously impaired movement [14]. Although some studies have investigated the efficacy of MWM in patients with shoulder conditions [15-17], only limited studies have examined the effects of MWM on people with scapular dyskinesis [18]. In these studies, the therapist applied force/glide on the scapula in combination with active shoulder movement.

As the scapula is linked to the neck anatomically and functionally, scapular mobilization with neck movements may have positive effects in patients with neck pain. To the best of the authors' knowledge, published research about the effects of scapulothoracic mobilization with neck movement in patients with neck pain is lacking. Therefore, the purpose of the current study was to investigate the effects of scapulothoracic mobilization technique on neck pain, ROM, and function in patients with neck pain who demonstrated scapular dyskinesis. The results of this study may add another insight into treating patients with neck pain by addressing MWM for the scapula to alter neck impairments. The null hypothesis was that there are no significant differences in neck pain, neck and scapula ROM, and function between patients with neck pain with scapular dyskinesis and comparison patients.

\section{Methods}

\section{Study Design and Setting}

This was a single-blind, randomized, clinical trial. Patients were blind to the treatment assignment. A randomization website (https://www.randomizer.org) was used to randomize patients into two treatment arms in a parallel design (1:1 ratio). Patients were alternately allocated according to the generated random number to either: (1) the experimental group (MWM + neck and scapulothoracic exercises + taping) or (2) the comparison group (neck and scapulothoracic exercises + taping). In this alternation type of allocation, patients were assigned to either group following a reciprocal pattern until all 40 patients were allocated [19]. 
The study was conducted at the hospital between April 2016 and February 2017. This study was approved by the Institutional Review Board (IRB) at the institution (IRB-PGS-2015-03-219) and registered at ClinicalTrials.gov (NCT03046160). The study followed the Declaration of Helsinki for human experimentation, and it was reported using the Consolidated Standards of Reporting Trials (CONSORT) guidelines. All patients provided a written consent form prior to participation, and their rights and confidentiality were protected.

\section{Sample size calculation}

The sample size was calculated using Tamaño de Muestra, Version 1.1, based on data from a previously published study [20]. Using the visual analogue scale (VAS) as a primary outcome, the following combination was used to determine the sample size: two-tailed t test with two groups, mean difference of $1.1 \mathrm{~cm}$, standard deviation of $0.7 \mathrm{~cm}$, alpha level of 0.05 , and power of $80 \%$. The estimated desired sample size was 40 , with a minimum of 20 patients per group.

\section{Participants}

Patients with neck pain, who were referred to the Department of Physical Therapy and agreed to participate in the study, were screened for eligibility. The therapist screened for scapular dyskinesis by using the Scapular Dyskinesis Test according to the procedure described previously [21]. In this test, the patient performed five repetitions of bilateral active shoulder flexion and active shoulder abduction, while holding a weight with either hand $(1.4 \mathrm{~kg}$ for patients weighing less than $68.1 \mathrm{~kg}$ or $2.3 \mathrm{~kg}$ for patients weighing more than $68.1 \mathrm{~kg}$ ). The therapist observed the movement while standing $2 \mathrm{~m}$ away from the patient, and assessed scapulohumeral rhythm through visual observation. Dyskinesis was determined by visual observation of scapular winging or dysrhythmia [22]. This test has good reliability and validity [21, 23].

Consecutive patients with neck pain and positive Scapular Dyskinesis Test were included in the study if they were adults (25-50 years of age), had neck pain 3 months or longer before the study start [24, 25], and scored 5 or more on the Neck Disability Index (NDI) [26]. Patients were excluded if they had neck or shoulder trauma or surgery, had cervical radiculopathy [27], had severe systemic disease, participated in an exercise program for the neck or scapular muscles at least 6 months before the study, consumed stimulants (caffeine and nicotine) or analgesics for at least 8 hours before the study, or had any contraindication to manual therapy.

\section{Outcome Measures}

The baseline evaluation included demographic data and outcome measures. All outcomes were measured at three stages: baseline at session 1, after treatment at session 3, and after treatment at session 6. All procedures of outcome measurement and intervention were done on the side of dyskinesis. If dyskinesis was bilateral, the procedures were performed on the side with greater dyskinesis.

\section{Primary outcome measures}


Pain. A 10-cm VAS with the endpoints marked "no pain" and "worst pain imaginable" was used to measure current pain intensity. The VAS is valid [28] and highly reliable [29] in measuring pain intensity.

Neck range of motion (ROM). An electronic system with dual inclinometers (microFET ${ }^{6 I M}$ ARCON TM Functional Capacity Evaluation, Michigan, USA) (Fig. 1) was used to measure cervical ROM, as described previously [30]. This system has demonstrated validity and good-to-high reliability ( $r=0.75$ to 0.92$)$ [30]. With the inclinometer fixed around their heads, patients were seated for all movements except for cervical rotation, which was taken with the patients in a supine position. Slight over-pressure was added to ensure maximum limits of the range [30]. An iPhone application (Clinometer, Peter Breitling, Version 3.3) was used to ensure a zero starting point before each measurement, as described previously [31]. The movements were performed in the following order with each patient: flexion, extension, left side bending, right side bending, left rotation, and right rotation. A 5-second rest was applied between each movement. Three measurements for each movement were performed, and the average was used for analysis.

\section{Secondary outcome measures}

Pressure pain threshold (PPT). A digital Algometer (Somedic AB, Farsta, Sweden) with a $1-\mathrm{cm}^{2}$ probe was used to quantify the lowest stimulus intensity at which the patient felt mechanical pain. This measure is valid [32] and has demonstrated moderate-to-good reliability [33]. The therapist applied pressure perpendicular to the skin at a rate of $40 \mathrm{kPa} / \mathrm{s}$. The patients were asked to press a button when the nonpainful pressure became painful. Three measurements were performed over the most tender point on the cervical spine, levator scapula, or upper trapezius with a 30-second rest period between each measurement. The mean of the thee readings was used for analysis [33].

Scapular ROM. A palpation meter with inclinometer (PALM) (Performance Attainment Associates, St. Paul, MN, USA) was used to measure scapular ROM in four directions: adduction, abduction, depression, and upward rotation. PALM has demonstrated good-to-excellent reliability [34]. Patients were seated on a short back-supported chair with hips and knees positioned at 90 degrees of flexion. Measurements were obtained in two positions:

1. Both shoulders in neutral with palms resting on ipsilateral thigh. Measurements were performed as an assessment of scapular position with three parameters: a) a horizontal line distance in resting position between the medial border of the scapula and the thoracic spine to measure scapular adduction, b) a horizontal line distance in arm elevation position in 60 degrees of scaption between the medial border of the scapula and the thoracic spine to measure scapular abduction, and $\mathrm{c}$ ) the distance between $\mathrm{C} 7$ and the acromion to measure scapular depression (Fig. 2, A and B) [34].

1. At 60 degrees of active shoulder abduction in the coronal plane, the therapist placed the arm at 60 degrees of abduction using a goniometer. The patient actively maintained this position with the aid of a marker tape placed on the adjacent wall. A 5-minute rest was ensured after each measurement to avoid the effects of fatigue. Measurements were taken as: a) from the root of the spine of the 
scapula to the spinous process of the adjacent thoracic spine, b) from the inferior angle of the scapula to the adjacent spinous process of the thoracic spine, and c) the distance from the scapular spine root to the inferior angle (Fig. 2, C, D and E). These three measurements were used to detect changes in scapular upward rotation using an equation from a previous study [35]. A positive value indicates the degree of upward scapular rotation, and a negative value indicates the degree of downward scapular rotation.

Neck Disability Index (NDI). The NDI is a 10-item, self-reported tool that is used to evaluate functional activities in patients with neck pain. The NDI assesses 10 items about subjective symptoms, activities of daily living, and discretionary activities of daily living. All items evaluate each activity on a scale from 0 (no disability) to 5 (full disability) with a total raw score $(0-50)$ or percentage score $(0-100 \%)$. The raw score was used in the current study as recommended by the developer. The NDI is reliable, valid, and responsive in patients with neck pain [36]. In our study, the Arabic version of NDI was used [37].

\section{Intervention}

Each patient received a total of six sessions over 2 to 3 weeks, with two to three sessions per week. Each session lasted for 30 to 60 minutes [38]. Patients in the experimental group received manual scapulothoracic MWM technique, in-session supervised scapulothoracic exercises, corrective elastic tape, and a carry-over home program with the same scapulothoracic exercises. The comparison group patients received the same regimen except for the scapulothoracic MWM technique.

Mobilization with Movement (MWM). The patient was sitting in an upright posture with the therapist standing at the opposite side of the affected scapula. Reaching across the trunk, the palm of the medial hand was over the clavicle with the lateral hand controlling the scapular glide. The humeral head was repositioned in a posterolateral glide with a gentle slight downward pull. Then, both hands applied corrective gliding force to reposition the scapula to the optimal position using an adduction force along with posterior and external rotations of the scapula. While maintaining this position, the patient was asked to move his/her neck toward restricted movement to the point of pain onset and return to the starting point. The therapist applied further pressure toward the restricted neck movement when needed. The technique was repeated 6 to 10 times. The MWM technique was initially indicated if the patient was able to achieve a considerably greater range and/or less or no pain. Then, the patient was asked to repeat the restricted neck movement 1 to 3 times independent of the scapular positioning by the therapist's hands. If the pain improved $(\geq 50 \%)$ with this movement, an additional 3 sets of 6 to 10 repetitions with the MWM technique were performed.[14] All patients in the experimental group were responsive to the MWM technique with varying degrees.

\section{Taping}

A 25-cm water-resistant synthetic, active, elastic and adhesive kinesiotape (KT TAPE PRO, KT Tape ${ }^{\circledR}$, USA) was used to help correct the scapular dyskinesis position. The patient was asked to hold the affected scapula down and move it medially toward the thoracic spine. An I-shaped elastic tape was 
applied over the muscle belly of the upper trapezius. The tape started with its anchor fixed anteriorly at the coracoid process and travelled with approximately $35-40 \%$ stretch posteriorly over the belly of the upper trapezius fibers and along the course of its lower fibers to the thoracic spine, where it was anchored. The tape was divided into five blocks of $5 \mathrm{~cm}$ each, and only $10 \mathrm{~cm}$ were stretched. The patients were asked to remove the tape a few hours before their next session [39].

\section{Scapulothoracic Exercises}

The exercises included cervical retraction, scapular retraction, deep neck flexors strengthening, and active ROM exercises of the neck in all directions. The exercises were performed during the session and at home by holding for 10 seconds for 10 repetitions five times every day.

\section{Statistical Analyses}

The statistical analyses were done using IBM SPSS for Mac (version 24.0, IBM, Amonk, New York, U.S.). Data normality was checked using the Shapiro-Wilk test. All outcome measures data were normally distributed at baseline except for scapular upward rotation. At baseline, an independent $t$ test was used to evaluate differences between both groups of continuous data, and a chi-square test was used for discrete data. All normal distribution testing was done on demographic data and baseline measurements of repeated measures. A mixed-model repeated measures analysis of variance (ANOVA) was used to analyze within- and between-group differences at baseline, after the third, and after the sixth sessions (repeated measures were set as GROUP with two levels, and TIME with three levels). Bonferonni post-hoc procedures were used for multiple comparisons of differences over the time levels. For scapular upward rotation, the Mann-Whitney $\mathrm{U}$ test was used to investigate between-group analysis, whereas the Wilcoxon test was used for within-group analysis. An intention-to-treat (ITT) type of analysis was applied, as all patients were analyzed in the group to which they were originally assigned. Uncompleted data of five patients due to drop-out were adjusted by mean values of the other group [40]. The statistical significance level was set at $p<0.05$.

\section{Results}

\section{Participant characteristics}

Figure 3 shows the flow diagram of the study recruitment. There were no significant differences between the experimental and comparison groups in all baseline demographic characteristics except for age, with an approximate 4 years' difference (Table 1). There were also no significant differences between the groups in all outcome measures at baseline (Table 2). 
Table 1

Demographic characteristics of patients in both groups at baseline.

\begin{tabular}{|c|c|c|c|}
\hline Variable & $\begin{array}{l}\text { Experimental group } \\
(n=20)\end{array}$ & $\begin{array}{l}\text { Comparison group } \\
(n=20)\end{array}$ & P-value \\
\hline Age (years)* & $33 \pm 6$ & $37 \pm 7$ & 0.040 \\
\hline Gender (Female / Male) & $16 / 4$ & $15 / 5$ & 0.705 \\
\hline $\operatorname{BMI}\left(\mathrm{kg} / \mathrm{m}^{2}\right)^{*}$ & $26.3 \pm 5.5$ & $27.5 \pm 6.2$ & 0.510 \\
\hline Pain duration (months)* & $13 \pm 10$ & $25 \pm 29$ & 0.103 \\
\hline \multicolumn{4}{|l|}{ Affected Scapula } \\
\hline Right & $11(27.5 \%)$ & $8(20 \%)$ & \multirow[t]{2}{*}{0.342} \\
\hline Left & $9(22.5 \%)$ & $12(30 \%)$ & \\
\hline \multicolumn{4}{|l|}{ Affected neck movement } \\
\hline Flexion & $11(27.5 \%)$ & $5(12.5 \%)$ & \multirow[t]{6}{*}{0.354} \\
\hline Extension & $2(5 \%)$ & $5(12.5)$ & \\
\hline Right rotation & $2(5 \%)$ & $2(5 \%)$ & \\
\hline Flex + Right rotation & $0(0 \%$ & $1(2.5)$ & \\
\hline Right side bending & $1(2.5 \%)$ & $3(7.5 \%)$ & \\
\hline Left side bending & $4(10 \%)$ & $4(10 \%)$ & \\
\hline \multicolumn{4}{|l|}{$\mathrm{BMI}=$ Body Mass Index } \\
\hline \multicolumn{4}{|c|}{ Values are expressed as frequency (percentage) otherwise stated. } \\
\hline * Values are expressed as & ean \pm standard devia & n. & \\
\hline
\end{tabular}


Table 2

Mean difference in within-group and between-group for all outcome measures.

\section{Within-group mean difference (95\% Confidence Interval)}

Outcome

Experimental group

E1 vs E3

$1.9 *(0.83$

2.9)

VAS $(\mathrm{cm})$
E1 vs E6

$3.1 *(2.1$

4.1)
Comparison group

C1 vs $\mathrm{C3}$

C1 vs C6

Cervical ROM

$\left({ }^{\circ}\right)$

\begin{tabular}{lllll} 
Flexion & $-1.2(-6.3$, & $-0.5(-5.4$, & $.33(-4.7,5.4)$ & $-3.4(-8.3$, \\
& $3.8)$ & $4.3)$ & & $1.4)$ \\
\hline Extension & $-4.4(-9.1$, & $-9.1^{*}(-14.2$, & $-7.2^{*}(-11.9$, & $-12.9^{*}$ \\
& $0.3)$ & $-4.0)$ & $-2.5)$ & $(-18.0,-7.9)$ \\
\hline Right rotation & $0.2(-4.8$, & $-6.2^{*}(-10.4$, & $-4.5(-9.4$, & $-9.2^{*}(-13.4$, \\
& $5.1)$ & $-1.9)$ & $0.5)$ & $-5.0)$ \\
\hline Left rotation & $0.3(-4.9$, & $-3.5(-8.3$, & $-1.4(-6.6$, & $-6.4(-11.3$, \\
& $5.5)$ & $1.4)$ & $3.8)$ & $-1.6)$ \\
\hline Right side & $-4.2(-8.4$, & $-5.3^{*}(-9.5$, & $-2.3(-6.5$, & $-6.0^{\star}(-10.2$, \\
bending & $0.1)$ & $-1.1)$ & $1.9)$ & $-1.8)$ \\
\hline Left side & $-4.0(-8.2$, & $-4.7 *(-8.4$, & $-1.9(-6.0$, & $-7.3^{*}(-11.0$, \\
bending & $0.1)$ & $-0.9)$ & $2.3)$ & $-3.7)$ \\
\hline PPT (kPa) & 12.3 & 17.7 & $-4.9(-46.6$, & -54.3 \\
& $(-29.5,54.1)$ & $(-38.5,73.9)$ & $36.9)$ & $(-110.5$, \\
\end{tabular}

Scapular

ROM

\begin{tabular}{|c|c|c|c|c|}
\hline $\begin{array}{l}\text { Upward } \\
\text { rotation }\left({ }^{\circ}\right)\end{array}$ & $\begin{array}{l}0.7(-5.7 \\
7.1)\end{array}$ & $\begin{array}{l}3.8(-1.6 \\
9.3)\end{array}$ & $\begin{array}{l}0.6(-5.8 \\
6.96)\end{array}$ & $\begin{array}{l}5.96(0.5, \\
11.4)\end{array}$ \\
\hline $\begin{array}{l}\text { Depression } \\
\text { (cm) }\end{array}$ & $\begin{array}{l}-0.4(-1.1 \\
0.3)\end{array}$ & $\begin{array}{l}0.5(-0.6 \\
0.7)\end{array}$ & $0.4(-0.3,1.1)$ & $\begin{array}{l}0.97(0.3, \\
1.6)\end{array}$ \\
\hline $\begin{array}{l}\text { Adduction } \\
\text { (cm) }\end{array}$ & $\begin{array}{l}0.4(-0.3 \\
0.98)\end{array}$ & $\begin{array}{l}0.3(-03 \\
0.9)\end{array}$ & $0.3(-0.6,0.7)$ & $\begin{array}{l}0.2(-0.4 \\
0.8)\end{array}$ \\
\hline
\end{tabular}

E1 $=$ experimental, session 1; E3 = experimental, session 3, E6 = experimental, session 6

$\mathrm{C} 1$ = comparison, session $1 ; \mathrm{C} 3$ = comparison, session $3, \mathrm{E} 6=$ comparison, session 6

VAS = visual analogue scale; $\mathrm{ROM}=$ range of motion; $\mathrm{PPT}=$ pressure pain threshold; $\mathrm{NDI}=$ neck disability index

$\$ 95 \%$ confidence interval values are based on the analysis of variance test. 
Within-group mean difference (95\% Confidence Interval)

\begin{tabular}{lllll|}
$\begin{array}{lll}\text { Abduction } \\
(\mathrm{cm})\end{array}$ & $0.4(-0.4$, & $0.7(-0.02$, & $0.3(-0.4,1.0)$ & $0.3(-0.4$, \\
\hline NDI $(/ 50)$ & $1.1)$ & $1.4)$ & & $1.4)$ \\
& $7.2^{*}$ & $10.6^{*}(5.6$, & $5.9^{*}$ & $10.3^{*}(5.3$, \\
& $(2.5,11.9)$ & $15.7)$ & $(1.2,10.7)$ & $15.4)$ \\
\hline
\end{tabular}

\section{Between-group mean difference (95\% Confidence Interval)}

\begin{tabular}{|llll|}
\hline Outcome & $\begin{array}{l}\text { Baseline [E1 vs } \\
\text { C1] }\end{array}$ & $\begin{array}{l}\text { Session 3 [E3 } \\
\text { vs C3] }\end{array}$ & $\begin{array}{l}\text { Session 6 [E6 } \\
\text { vs C6] }\end{array}$ \\
\hline VAS $(\mathrm{cm})$ & $0.8(-0.4,1.9)$ & $0.8(-0.67,2.7)$ & $1.3(-0.1,2.7)$ \\
\hline $\begin{array}{l}\text { Cervical ROM } \\
\left({ }^{\circ}\right.\end{array}$ & & & \\
\hline Flexion & $1.8(-4.9,8.6)$ & $-1.6(-8.8,5.6)$ & $2.9(-3.96,9.7)$ \\
\hline Extension & $4.9(-2.2,12.2)$ & $2.8(-3.9,9.4)$ & $3.9(-3.3,11.1)$ \\
\hline Right rotation & $5.5(-0.7,11.7)$ & $4.6(-2.4,11.6)$ & $3(-2.9,8.97)$ \\
\hline Left rotation & $4.8(-1.97,11.6)$ & $1.7(-5.7,9)$ & $2.9(-3.9,9.8)$ \\
\hline $\begin{array}{l}\text { Right side } \\
\text { bending }\end{array}$ & $0.1(-4.3,4.4)$ & $-1.9(-7.8,4.1)$ & $0.7(-5.2,6.7)$ \\
\hline $\begin{array}{l}\text { Left side } \\
\text { bending }\end{array}$ & $0.3(-4.7,5.3)$ & $-2.2(-8.1,3.7)$ & $2.7(-2.7,7.96)$ \\
\hline \begin{tabular}{l} 
PPT $(\mathrm{kPa})$ \\
\hline
\end{tabular} & $\begin{array}{l}18.6(-81.9, \\
119.1)\end{array}$ & $\begin{array}{l}17.1(-41.9, \\
76.2)\end{array}$ & $72(-7.5,155.6)$ \\
\hline
\end{tabular}

\section{Scapular}

ROM

\begin{tabular}{llll}
$\begin{array}{l}\text { Upward } \\
\text { rotation }\left(^{\circ}\right)\end{array}$ & $-2.6(-9.4,4.2)^{\$}$ & $0.1(-8.9,9.1)$ & $-2.1(-9.9,5.6)$ \\
\hline $\begin{array}{l}\text { Depression } \\
(\mathrm{cm})\end{array}$ & $-0.5(-1.6,0.7)$ & $-0.8(-1.8,0.15)$ & $-0.9(-1.9,0.01)$ \\
$\begin{array}{l}\text { Adduction } \\
(\mathrm{cm})\end{array}$ & $0.3(-0.6,1.2)$ & $0.3(-0.6,1.2)$ & $0.14(-0.7,1.0)$
\end{tabular}

E1 = experimental, session 1; E3 = experimental, session 3, E6 = experimental, session 6

$\mathrm{C} 1$ = comparison, session 1; C3 = comparison, session 3, E6 = comparison, session 6

VAS = visual analogue scale; $\mathrm{ROM}=$ range of motion; $\mathrm{PPT}=$ pressure pain threshold; $\mathrm{NDI}=$ neck disability index

$\$ 95 \%$ confidence interval values are based on the analysis of variance test. 


\section{Within-group mean difference ( $95 \%$ Confidence Interval)}
Abduction
$-0.1(-1.0,0.9)$
$0.1(-0.9,1.1)$
$0.4(-0.6,1.4)$
$(\mathrm{cm})$

NDI (/50)

$-1.7(-9.6,6.3)$

$1.3(-5.4,8.0)$

$0.3(-6.9,7.5)$

$\mathrm{E} 1=$ experimental, session 1; E3 = experimental, session 3, E6 = experimental, session 6

$\mathrm{C} 1=$ comparison, session $1 ; \mathrm{C} 3=$ comparison, session $3, \mathrm{E} 6=$ comparison, session 6

VAS = visual analogue scale; ROM = range of motion; $\mathrm{PPT}$ = pressure pain threshold; $\mathrm{NDI}=$ neck disability index

$\$ 95 \%$ confidence interval values are based on the analysis of variance test.

\section{Outcome measures}

Table 2 shows the results of all outcome measures for both within- and between-group analysis.

Regarding pain intensity, the mixed-model ANOVA showed a significant group-by-time interaction [F (2, $37)=19.672, p<.001]$. Compared with the baseline measurement, pain decreased significantly in both groups at both the third and the sixth sessions $(p \leq 0.04)$. The decrease in pain was more than the minimal clinically important difference (MCID) of $1.4 \mathrm{~cm},[41]$ except for the comparison group at the third session, where the decrease in pain was $1.1 \mathrm{~cm}$. There was no significant difference between both groups at any stage.

As for cervical ROM, the mixed-model ANOVA showed no significant group-by-time interaction for flexion $[F(2,37)=0.155, p=0.857]$ and left rotation $[F(2,37)=1.347, p=0.273]$. On the other hand, the ANOVA demonstrated significant group-by-time interactions for extension $[F(2,37)=7.119, p=0.002]$, right rotation $[F(2,37)=9.238, p=0.001]$, right side bending $[F(2,37)=3.833, p=0.031]$, and left side bending $[F(2,37)=3.664, p=0.035]$. Compared with the baseline measurement, the ROM for cervical extension, right rotation, right side bending, and left side bending increased significantly at the sixth session in both groups ( $p \leq 0.02$ ) as well as at the third session for cervical extension in the comparison group $(p<0.05)$. There were no significant differences in any movement between both groups at any stage.

Concerning PPT, the mixed-model ANOVA analysis showed no significant group-by-time interaction [F (2, $37)=0.278, p=0.759]$. For scapular ROM, the mixed-model ANOVA showed no significant group-by-time interactions for adduction $[F(2,37)=0.843, p=0.439]$, abduction $[F(2,37)=1.864, p=0.169]$, and depression $[F(2,37)=1.015, p=0.372]$. Similarly, the Mann-Whitney $U$ test demonstrated no significant interaction for upward rotation between the groups after the third session $[U=163, Z=-1.001, p=0.327]$ or the sixth session $[U=195, Z=-0.122, p=0.904]$.

Regarding NDI, the mixed-model ANOVA showed a significant group-by-time interaction $[F(2,37)=8.799$, $p=0.001]$. Neck disability decreased significantly in both groups at the third and sixth sessions $(p \leq$ 
0.016). This improvement was more than the MDC of 5 points in both groups at both sessions.[36] There was no significant difference between both groups at any stage.

\section{Discussion}

This study examined the efficacy of adding mobilization of the scapula with active neck movement (i.e., MWM) to scapulothoracic exercises and taping in patients with neck pain who presented with scapular dyskinesis. Pain, cervical and scapula ROM, and NDI improved with the implementation of exercises and corrective tape either with or without MWM to the scapula. Thus, no significant differences were found between the group who received scapular MWM with scapulothoracic exercises and tape and the group who received only the scapulothoracic exercises and tape.

The improvement in pain in our study may partially be explained by the effects of exercises and/or taping on scapulothoracic correction, which may facilitate regaining normal patterns of muscular activity through soft-tissue attachments of the scapula to both the cervical and thoracic spine [42]. Another explanation may be attributed to the fact that altered scapular kinematics has been found to contribute to generate tissue mechano-sensitization and an eventual structural hypersensitivity [43]. Moreover, a decrease in the compressive forces on the cervical facets may have resulted in decreased neck pain [44]. In previous studies, neck pain as measured with VAS and/or PPT improved after passive correction of scapular downward rotation [44], active correction of the scapula [22], scapular mobilization [45], and scapular stabilization exercises [46, 47]. A more recent study, however, showed that either scapular stabilization or neck-focused exercises in combination with manual therapy decreased pain in patients with neck pain [48].

In our study, cervical ROM improved statistically in extension (range: $9.1^{\circ}-12.9^{\circ}$ ), right rotation (range: $6.2^{\circ}-9.2^{\circ}$ ), right side bending (range: $5.3^{\circ}-6.0^{\circ}$ ), and left side bending (range: $4.7^{\circ}-7.3^{\circ}$ ) in both groups at mainly the sixth session. However, these values did not reach the MDC values: $16^{\circ}$ of extension, $13^{\circ}$ of right rotation, $10^{\circ}$ of right side bending, and $12^{\circ}$ of left side bending [49]. Ha, Kwon [44] found that passive correction of the scapula significantly improved cervical rotation ROM (right: $12.78^{\circ}$, left: $14.17^{\circ}$ ) in patients with neck pain who had bilateral scapular downward-rotation syndrome compared with patients who did not have the syndrome. The authors, however, did not report the baseline ROM in either group to enable the reader to compare the differences in the ROM before and after correction of the scapula.

For scapular ROM, the current study showed no improvement in any movement. No previous studies have examined the effects of MWM or scapulothoracic exercises on scapular dyskinesis in patients with neck pain. A recent systematic review found that several studies reported beneficial effects of therapeutic exercises with or without manual therapy on scapular dyskinesis in patients with shoulder impingement syndrome and in asymptomatic people. However, the authors concluded that the methodologic quality of the studies was debatable, and the evidence for the effect of exercise on scapular dyskinesis in these populations is conflicting [50]. 
In our study, NDI improved in both groups at both the third and sixth sessions. Our results are in agreement with the results of Im, Kim [46] who found that scapular stabilization exercises decreased NDI in patients with neck pain. On the other hand, a later study found that manual therapy techniques plus scapular stabilization exercises or neck-focused exercises improved NDI in nonspecific neck pain [48].

\section{Study limitations}

A limitation of this study was that the examiners were not blinded to the patients' measurements, which may have biased the results. In addition, a comparison group that received no treatment was not included in the study. Thus, someone may argue that the observed improvements occurred naturally.

\section{Conclusion}

The results of this study found that the patients with chronic neck pain accompanied by scapular dyskinesis in both the MWM and comparison groups improved similarly in pain and disability. The addition of a scapulothoracic MWM did not seem to add a supplementary enhancement to the exercises and corrective tape treatment regimen for the 2-week period.

\section{Declarations}

\section{Ethics approval and consent to participate}

This study was approved by the Institutional Review Board (IRB) at Imam Abdulrahman Bin Fiasal University (IRB-PGS-2015-03-219) and retrospectively registered at ClinicalTrials.gov (NCT03046160). All patients provided a written consent form prior to participation, and their rights and confidentiality were protected.

\section{Consent for publication}

Not applicable.

\section{Availability of data and materials}

The datasets used and/or analysed during the current study are available from the corresponding author on reasonable request.

\section{Competing interests}

The authors declare that they have no competing interests.

\section{Funding}

This research did not receive any specific grant from funding agencies in the public, commercial, or notfor-profit sectors. 


\section{Authors' contributions}

AIA concepted and designed the study; recruited the patients; collected data; analyzed and interpreted the data. Together with AIA, AMA concepted and designed the study; analyzed and interpreted data. Both authors contributed to writing the manuscript; read and approved the final manuscript.

\section{Acknowledgements}

The authors would like to thank Mr. Mohammed AlSenni, Ms. Amani AlHashash, Mr. Ahmad Busaleh and Mr. Hussain AlSalem for their assistance with data collection. Special thanks go to Dr. Abeer Hegazy for her assistance in patients' recruitment.

\section{References}

1. Hoy D, March L, Woolf A, Blyth F, Brooks P, Smith E, et al. The global burden of neck pain: Estimates from the global burden of disease 2010 study. Ann Rheum Dis. 2014;73(7):1309-15.

2. Alshami AM. Prevalence of spinal disorders and their relationships with age and gender. Saudi Med J. 2015;36(6):725-30.

3. Blanpied PR, Gross AR, Elliott JM, Devaney LL, Clewley D, Walton DM, et al. Neck Pain: Revision 2017. J Orthop Sports Phys Ther. 2017;47(7):A1-83.

4. Cagnie B, Struyf F, Cools A, Castelein B, Danneels L, O'Leary S. The relevance of scapular dysfunction in neck pain: A brief commentary. J Orthop Sports Phys Ther. 2014;44(6):435-9.

5. Kibler WB, Ludewig PM, McClure PW, Michener LA, Bak K, Sciascia AD. Clinical implications of scapular dyskinesis in shoulder injury: the 2013 consensus statement from the 'Scapular Summit'. Br J Sports Med. 2013;47(14):877-85.

6. Illyes A, Kiss RM. Kinematic and muscle activity characteristics of multidirectional shoulder joint instability during elevation. Knee surgery, sports traumatology, arthroscopy: official journal of the ESSKA. 2006;14(7):673-85.

7. Huang TS, Huang CY, Ou HL, Lin JJ. Scapular dyskinesis: Patterns, functional disability and associated factors in people with shoulder disorders. Man Ther. 2016;26:165-71.

8. Laudner KG, Myers JB, Pasquale MR, Bradley JP, Lephart SM. Scapular dysfunction in throwers with pathologic internal impingement. J Orthop Sports Phys Ther. 2006;36(7):485-94.

9. Ludewig PM, Reynolds JF. The association of scapular kinematics and glenohumeral joint pathologies. J Orthop Sports Phys Ther. 2009;39(2):90-104.

10. Amorim CS, Gracitelli ME, Marques AP, Alves VL. Effectiveness of global postural reeducation compared to segmental exercises on function, pain, and quality of life of patients with scapular dyskinesis associated with neck pain: A preliminary clinical trial. J Manipulative Physiol Ther. 2014;37(6):441-7. 
11. Castelein B, Cools A, Parlevliet T, Cagnie B. Are chronic neck pain, scapular dyskinesis and altered scapulothoracic muscle activity interrelated?: A case-control study with surface and fine-wire EMG. J Electromyogr Kinesiol. 2016;31:136-43.

12. Zabihhosseinian M, Holmes MW, Howarth S, Ferguson B, Murphy B. Neck muscle fatigue differentially alters scapular and humeral kinematics during humeral elevation in subclinical neck pain participants versus healthy controls. J Electromyogr Kinesiol. 2017;33:73-82.

13. Ellenbecker TS, Cools A. Rehabilitation of shoulder impingement syndrome and rotator cuff injuries: An evidence-based review. Br J Sports Med. 2010;44(5):319-27.

14. Mulligan B. Manual therapy "NAGS", "SNAGS", "MWMS" etc. 6th ed. Wellington: Plane View Services; 2010.

15. Teys P, Bisset L, Collins N, Coombes B, Vicenzino B. One-week time course of the effects of Mulligan's Mobilisation with Movement and taping in painful shoulders. Man Ther. 2013;18(5):372-7.

16. Dabholkar A, Dabholkar T, Yardi S. Efficacy of scapular movement with mobilization in patients with shoulder impingement. Indian J Physiother Occup Ther. 2013;7(3):20-4.

17. Djordjevic OC, Vukicevic D, Katunac L, Jovic S. Mobilization with movement and kinesiotaping compared with a supervised exercise program for painful shoulder: results of a clinical trial. $\mathrm{J}$ Manipulative Physiol Ther. 2012;35(6):454-63.

18. Kumar GPY, Chahar KH, Kumar M, Kumar S. Sudheer. Effect of mobilization with movement and corrective exercisesin humeral and scapular position among swimmers with scapular dyskinesis Randomized clinical trial. Inter J of Ther Rehab Research. 2017;6(2):227-32.

19. Davidson I, Hillier VF. Comparison of Four Methods of Allocation for Clinical Trials with Small Sample Sizes. Physiotherapy. 2002;88(12):722-9.

20. Cleland JA, Childs JD, McRae M, Palmer JA, Stowell T. Immediate effects of thoracic manipulation in patients with neck pain: a randomized clinical trial. Man Ther. 2005;10(2):127-35.

21. McClure $P$, Tate AR, Kareha $S$, Irwin D, Zlupko E. A clinical method for identifying scapular dyskinesis, Part 1: Reliability. J Athl Train. 2009;44(2):160-4.

22. Lluch E, Arguisuelas MD, Calvente Quesada O, Martinez Noguera E, Peiro Puchades M, Perez Rodriguez JA, et al. Immediate effects of active versus passive scapular correction on pain and pressure pain threshold in patients with chronic neck pain. J Manipulative Physiol Ther. 2014;37(9):660-6.

23. Tate AR, McClure P, Kareha $S$, Irwin D, Barbe MF. A clinical method for identifying scapular dyskinesis, part 2: validity. J Athl Train. 2009;44(2):165-73.

24. O'Leary S, Falla D, Elliott JM, Jull G. Muscle dysfunction in cervical spine pain: implications for assessment and management. J Orthop Sports Phys Ther. 2009;39(5):324-33.

25. Panjabi MM, Cholewicki J, Nibu K, Grauer J, Babat LB, Dvorak J. Critical load of the human cervical spine: an in vitro experimental study. Clin Biomech. 1998;13(1):11-7. 
26. Vernon H. The Neck Disability Index: State-of-the-art, 1991-2008. J Manipulative Physiol Ther. 2008;31(7):491-502.

27. Corey DL, Comeau D. Cervical radiculopathy. Med Clin North Am. 2014;98(4):791-9.

28. Ferreira-Valente MA, Pais-Ribeiro JL, Jensen MP. Validity of four pain intensity rating scales. Pain. 2011;152(10):2399-404.

29. Price DD, McGrath PA, Rafii A, Buckingham B. The validation of visual analogue scales as ratio scale measures for chronic and experimental pain. Pain. 1983;17(1):45-56.

30. Law EY, Chiu TT. Measurement of cervical range of motion (CROM) by electronic CROM goniometer: A test of reliability and validity. J Back Musculoskelet Rehabil. 2013;26(2):141-8.

31. Tousignant-Laflamme Y, Boutin N, Dion AM, Vallee CA. Reliability and criterion validity of two applications of the iPhone to measure cervical range of motion in healthy participants. $J$ Neuroeng Rehabil. 2013;10(1):69.

32. Kinser AM, Sands WA, Stone MH. Reliability and validity of a pressure algometer. J Strength Cond Res. 2009;23(1):312-4.

33. Ylinen J, Nykanen M, Kautiainen $\mathrm{H}$, Hakkinen A. Evaluation of repeatability of pressure algometry on the neck muscles for clinical use. Man Ther. 2007;12(2):192-7.

34. da Costa BR, Armijo-Olivo S, Gadotti I, Warren S, Reid DC, Magee DJ. Reliability of scapular positioning measurement procedure using the palpation meter (PALM). Physiotherapy. 2010;96(1):59-67.

35. Mackenzie TA, Bdaiwi Alya H, Lee C, Ann. The palpation meter (palm) is reliable for measuring scapular upward rotation in the coronal plane. Int J Phys Edu Sports Health. 2015;2(2):54-9.

36. MacDermid JC, Walton DM, Avery S, Blanchard A, Etruw E, McAlpine C, et al. Measurement properties of the neck disability index: A systematic review. J Orthop Sports Phys Ther. 2009;39(5):400-17.

37. Shaheen AA, Omar MT, Vernon H. Cross-cultural adaptation, reliability, and validity of the Arabic version of neck disability index in patients with neck pain. Spine. 2013;38(10):609-15.

38. Miller J, Gross A, D'Sylva J, Burnie SJ, Goldsmith CH, Graham N, et al. Manual therapy and exercise for neck pain: A systematic review. Man Ther. 2010;15(4):334-54.

39. Han JT, Lee JH, Yoon $\mathrm{CH}$. The mechanical effect of kinesiology tape on rounded shoulder posture in seated male workers: a single-blinded randomized controlled pilot study. Physiother Theory Pract. 2015;31(2):120-5.

40. Armijo-Olivo S, Warren S, Magee D. Intention to treat analysis, compliance, drop-outs and how to deal with missing data in clinical research: A review. Phys Ther Rev. 2009;14(1):36-49.

41. Tashjian RZ, Deloach J, Porucznik CA, Powell AP. Minimal clinically important differences (MCID) and patient acceptable symptomatic state (PASS) for visual analog scales (VAS) measuring pain in patients treated for rotator cuff disease. J Shoulder Elbow Surg. 2009;18(6):927-32.

42. Wegner S, Jull G, O'Leary S, Johnston V. The effect of a scapular postural correction strategy on trapezius activity in patients with neck pain. Man Ther. 2010;15(6):562-6. 
43. Martinez-Merinero P, Lluch E, Gallezo-Izquierdo T, Pecos-Martin D, Plaza-Manzano G, Nunez-Nagy S, et al. The influence of a depressed scapular alignment on upper limb neural tissue mechanosensitivity and local pressure pain sensitivity. Musculoskelet Sci Pract. 2017;29:60-5.

44. Ha SM, Kwon OY, Yi CH, Jeon HS, Lee WH. Effects of passive correction of scapular position on pain, proprioception, and range of motion in neck-pain patients with bilateral scapular downward-rotation syndrome. Man Ther. 2011;16(6):585-9.

45. Kılınç HE, Harput G, Baltacı G, Ince D. Short term effects of mobilization techniques on neck pain and deep neck flexor muscle endurance in patients with mechanical chronic neck pain. Orthop J Sports Med. 2014;2(3_suppl):2325967114.

46. Im B, Kim Y, Chung Y, Hwang S. Effects of scapular stabilization exercise on neck posture and muscle activation in individuals with neck pain and forward head posture. J Phys Ther Sci. 2016;28(3):951-5.

47. Celenay ST, Kaya DO, Akbayrak T. Cervical and scapulothoracic stabilization exercises with and without connective tissue massage for chronic mechanical neck pain: A prospective, randomised controlled trial. Man Ther. 2016;21:144-50.

48. Yildiz TI, Turgut E, Duzgun I. Neck and scapula-focused exercise training on patients with nonspecific neck pain: A randomized controlled trial. J Sport Rehabil. 2018;27(5):403-12.

49. Piva SR, Erhard RE, Childs JD, Browder DA. Inter-tester reliability of passive intervertebral and active movements of the cervical spine. Man Ther. 2006;11(4):321-30.

50. Nodehi Moghadam A, Rahnama L, Noorizadeh Dehkordi S, Abdollahi S. Exercise therapy may affect scapular position and motion in individuals with scapular dyskinesis: a systematic review of clinical trials. J Shoulder Elbow Surg. 2020;29(1):e29-36.

51. Bakkum BW. Surface anatomy of the back and vertebral levels of clinically important structures. In: Cramer GD, Darby SA, editors. Clinical Anatomy of the Spine, Spinal Cord, and ANS. 3rd ed. St. Louis: Mosby, Inc.; 2014. pp. 1-14.

\section{Figures}




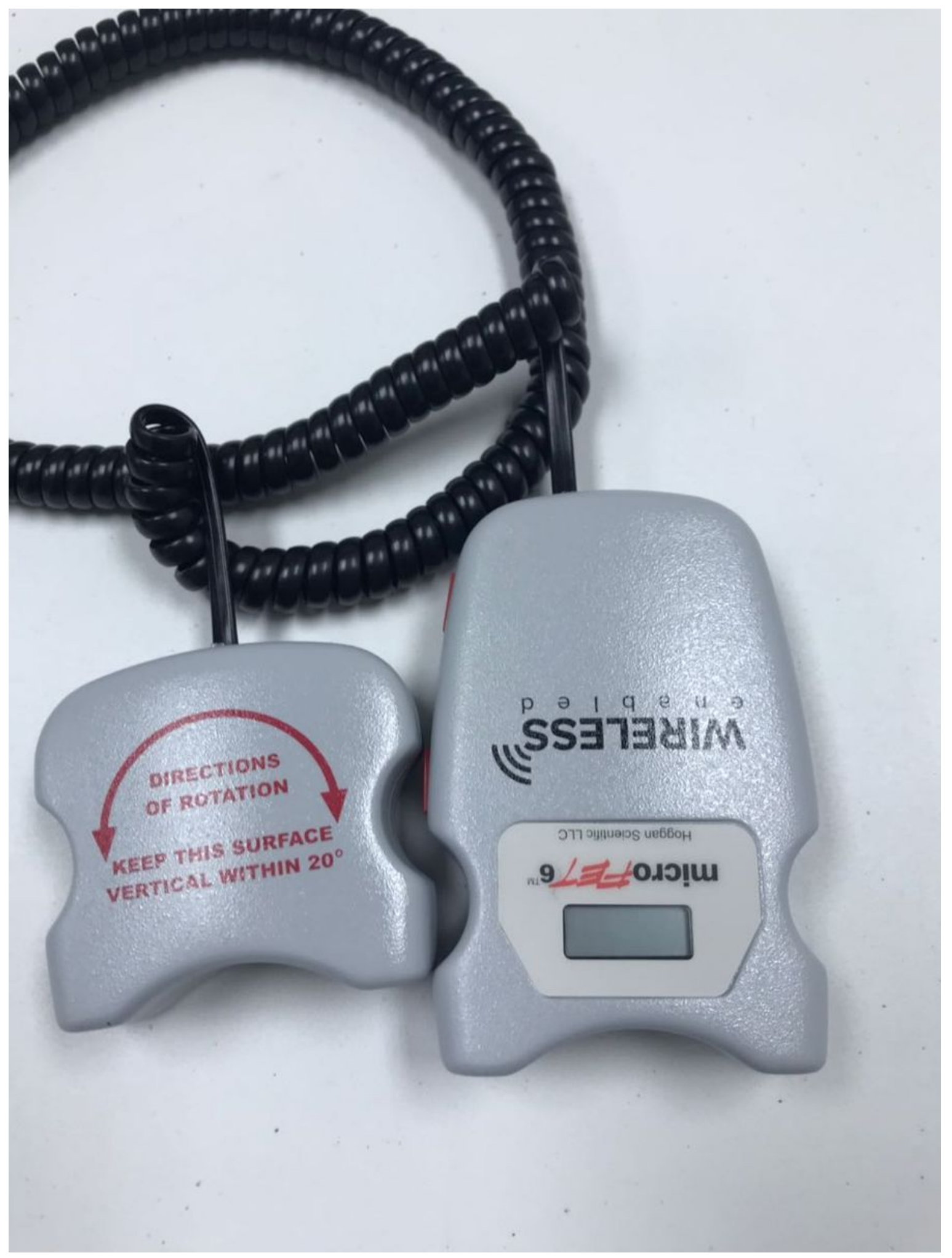

Figure 1

Electronic goniometer to measure neck range of motion. 


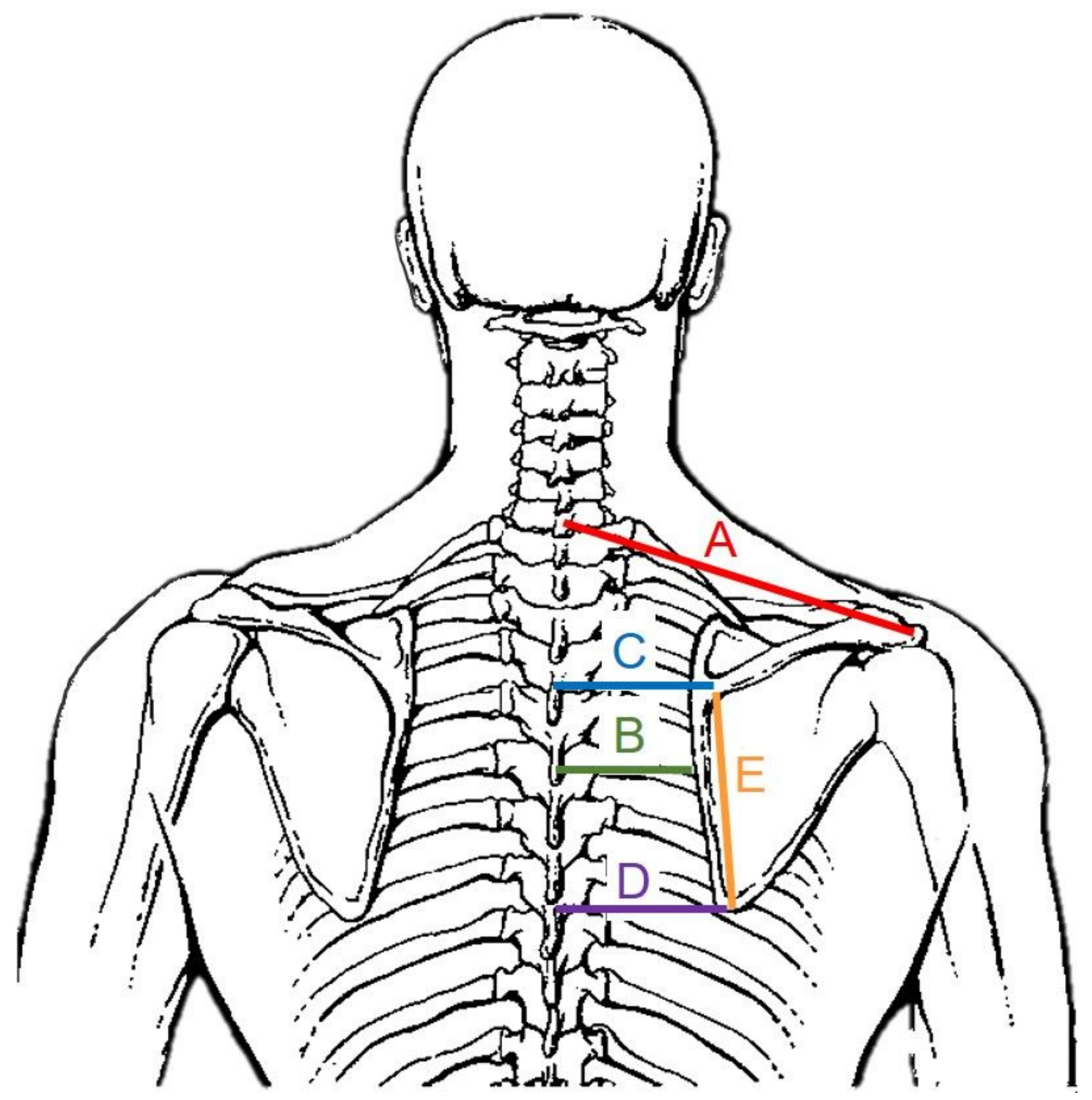

Figure 2

Landmarks of measurement of scapular range of motion. A: distance between $\mathrm{C} 7$ and the acromion (depression), B: distance between scapular medial border and the thoracic spine (adduction/abduction), C: from the root of the spine of the scapula to the thoracic spine (upward rotation), D: from the inferior angle of the scapula to the thoracic spine (upward rotation), and E: distance between the scapular spine root and the inferior angle (upward rotation). Adapted with permission from Bakkum.[51] 


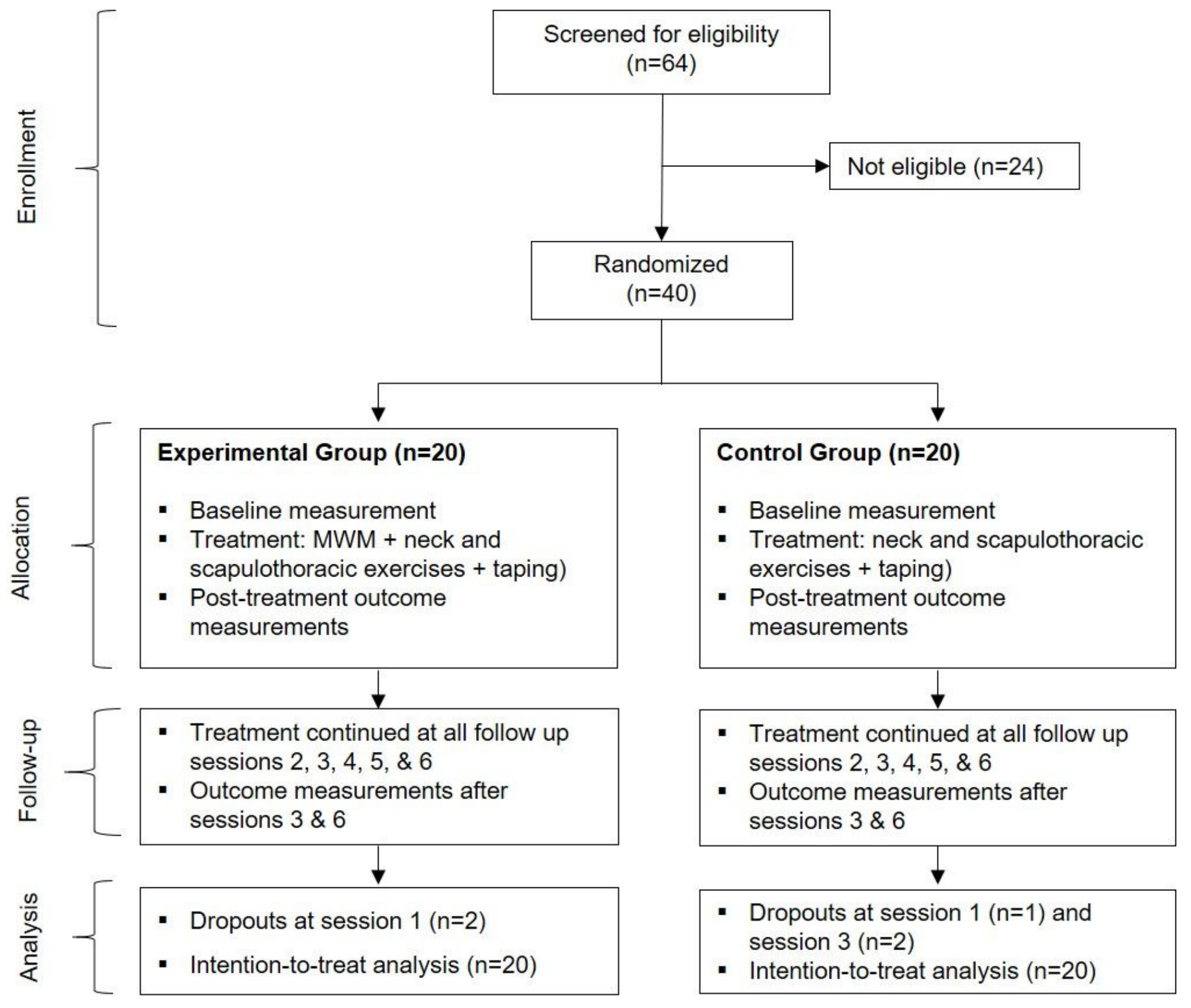

Figure 3

CONSORT flow diagram of the study. MWM, mobilization with movement

\section{Supplementary Files}

This is a list of supplementary files associated with this preprint. Click to download.

- downloadCertificate.pdf 